\title{
Los derechos de usuarios y consumidores son derechos humanos
}

\section{Human Rights are the Rights of Users and \\ Consumers}

Carlos Eduardo Tambussi*

http://dx.doi.org/10.21503/lex.v12i13.38

* Abogado, Universidad de Buenos Aires (1991), Orientación en Derecho Administrativo (Plan Res. 809/85). Auditor Legal de la Administración de Parques Nacionales (20072010) Procurador Adjunto de Asuntos Patrimoniales y Fiscales del Gobierno de la Ciudad Autónoma de Buenos Aires (2010-2012). Secretario del Juzgado Nro. 18, Secretaría 35 del Fuero Contencioso Administrativo y Tributario de la CABA. Profesor Adjunto Interino de la Universidad de Buenos Aires, Facultad de Derecho, cátedra de Derechos Humanos y Garantías. Profesor a cargo del curso Protección Constitucional de Consumidores y Usuarios del Ciclo Profesional Orientado en la Facultad de Derecho (Universidad de Buenos Aires). Profesor Adjunto de Derechos del Consumidor de la Universidad de Belgrano. Miembro del Instituto de Derecho de Usuarios y Consumidores del Colegio Público de Abogados de la Capital Federal. Presidente de la Comisión de Derecho del Consumidor de la Asociación de Abogados de Buenos Aires. Autor del libro El consumo como derecho humano, publicado por Editorial Universidad (2009), y de varios artículos de la especialidad. Correo electrónico: cetambu@uolsinectis.com.ar

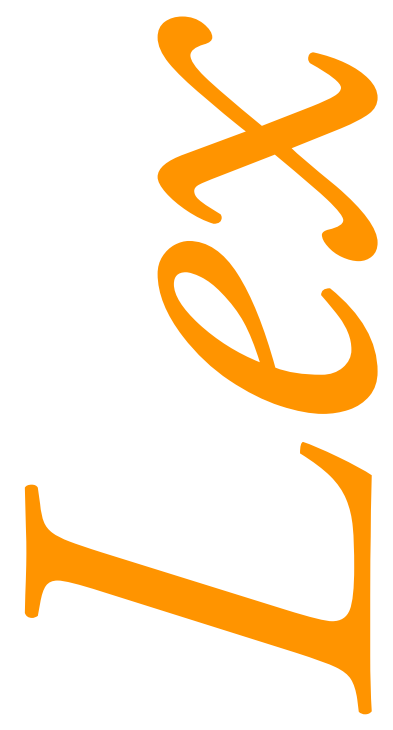




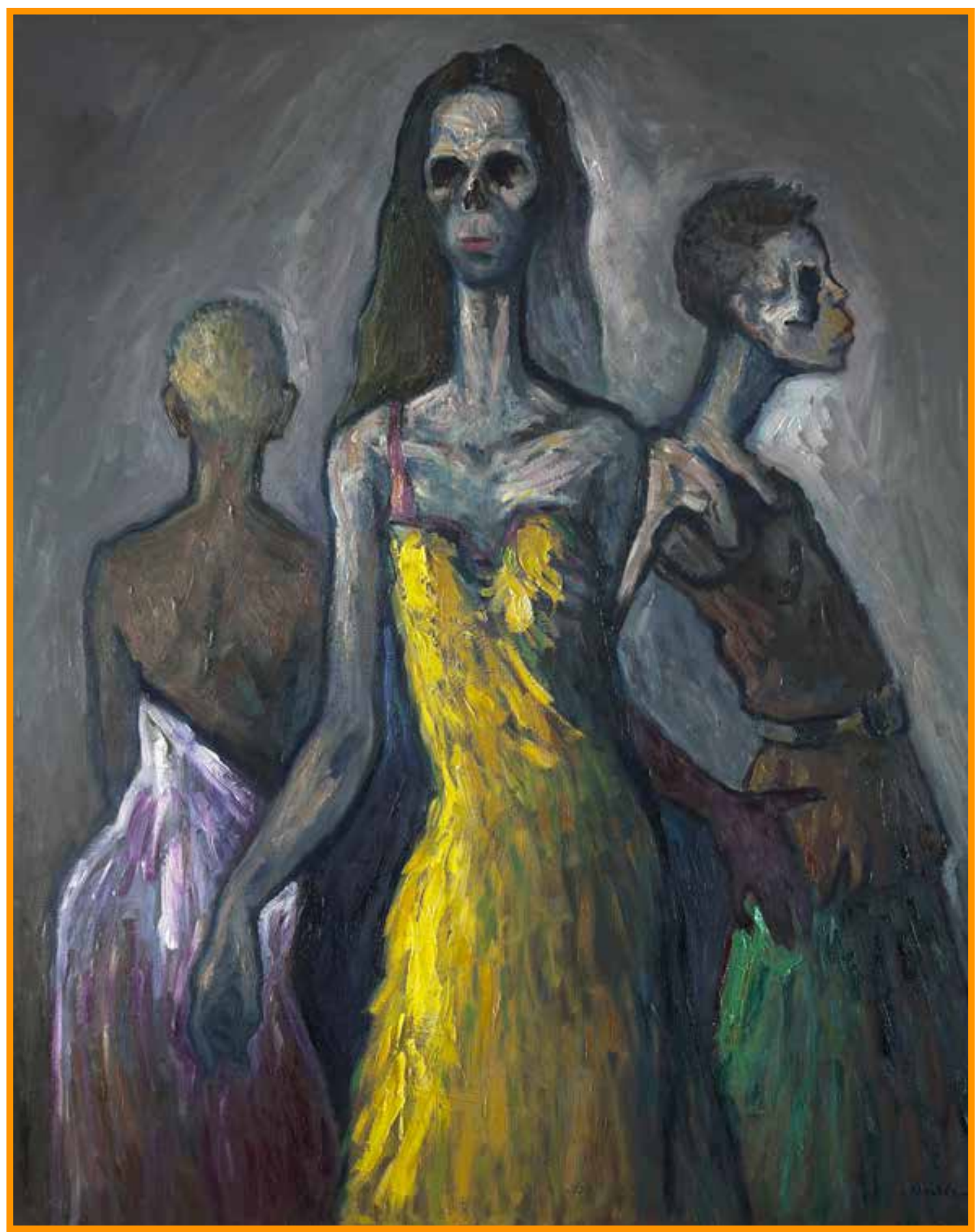

Fashion II. Óleo sobre tela $(150$ x $135 \mathrm{~cm})$. 


\section{RESUMEN}

El objetivo de este artículo es contribuir a confirmar que los derechos de los llamados usuarios y consumidores en la relación de consumo, así como el derecho de acceso al consumo mismo, forman parte de ese logro de la civilización que consiste en el amplio espectro que conforman los llamados "derechos humanos", gracias a su desarrollo original en el derecho internacional público, su impregnación en las normas internas de los Estados y la progresividad del reconocimiento y protección de los mismos. ${ }^{1}$ Se describe y analiza el hecho de que la relación de consumo, entendida como el vínculo jurídico entre el proveedor y el consumidor o usuario, se encuentra transversalmente atravesada por bienes jurídicos o valores que su normativa tutela, y que contemplan el derecho a la vida y a la dignidad y el derecho a la salud y la seguridad, a la libertad de elección, a la protección de los intereses económicos y al trato equitativo y digno ${ }^{2}$. Todos esos valores ${ }^{3}$ están presentes en el fenómeno del consumo y su derecho regulador, nacido para encauzar la relación de consumo en el respeto a los imperativos que emanan de la dignidad humana.

Palabras clave: consumidores, usuarios, derechos humanos, bienes y servicios.

1 En algunos precedentes jurisprudenciales, la relación ha sido definida como de género a especie. (Ver Cámara Nacional de Apelaciones en lo Comercial, en pleno "s/Competencia del fuero comercial en los supuestos de ejecución de títulos cambiarios en que se invoquen involucrados derechos de consumidores" (Expdte. S. 2093/09), 29/6/2011, voto del Dr. Pablo Heredia, donde expresamente se dice: "Conviene recordar que los derechos del consumidor son una especie del género "derechos humanos" (Cfr. C. Ghersi y otros. Derecho y responsabilidades de las empresas y consumidores. Buenos Aires: Ediciones Organización Mora Libros, 1994, pp. 22/23)”.

2 "La noción de derechos humanos se corresponde con la afirmación de la dignidad de la persona frente al Estado. El poder público debe ejercerse al servicio del ser humano: no puede ser empleado lícitamente para ofender atributos inherentes a la persona y debe ser vehículo para que ella pueda vivir en sociedad en condiciones cónsonas con la misma dignidad que le es consustancial”. Pedro Nikken. Manual de derechos humanos. Selección de materiales. Centro de Estudios de Derechos Humanos, Universidad Central de Venezuela, 2008.

3 Podríamos afirmar con Eduardo Torres Buteler que todo el conjunto del sistema de los derechos humanos contribuye a hacer efectivos los derechos del consumidor (http://bibdigital.uccor.edu.ar/ojs/ index.php/RFD/article/view/739/591) 


\begin{abstract}
The aim of this article is to help confirm that the rights of so-called users and consumers in the relationship of consumption, as well as the right of access to the same consumption, are part of that achievement of civilization consisting of the broad spectrum that make up the so-called "human rights", thanks to its original development in public international law, its impregnation in the internal rules of the States and the progressiveness of the recognition and protection of the same. It describes and analyses the fact of the relationship of consumption, understood as the legal link between the supplier and the consumer or user, it is situated transversely crossed by legal goods or values that its regulations are protected, and which include the right to life and dignity and the right to health and safety, freedom of choice and decent treatment and the protection of economic interests. All these values are present in the phenomenon of the consumption and its levy, born to steer the relationship of consumption in regard to the imperatives arising from human dignity.
\end{abstract}

Key words: consumers, users, human rights, goods and services. 


\section{INTRODUCCIÓN. LA RELACIÓN DE CONSUMO INVOLUCRA BIENES JURÍDICAMENTE PROTEGIDOS $\mathrm{Y}$ VALORES PROPIOS $\mathrm{E}$ INTERNACIONALMENTE ACEPTADOS COMO PARTE DE LOS DERECHOS HUMANOS}

El derecho del consumo comprende un aspecto fundamental de nuestras vidas. Al consumir (en cualquiera de sus niveles) procuramos satisfacer al menos, e insoslayablemente, nuestras necesidades elementales y alcanzar una adecuada calidad de vida. Ello nos lleva a procurar en el ámbito llamado mercado (como espacio de intercambio), los bienes y servicios que necesitamos. Somos, como consumidores, destinatarios finales de todos los bienes y del producto de la actividad comercial. ${ }^{4}$

Esa ineludible y constante excursión al mercado hace del derecho de consumidores y usuarios el más cotidiano de los derechos, y conforma una disciplina jurídica cuyo objeto de estudio se verifica diariamente con el desenvolvimiento de nuestras actividades.

A esa tarea acudimos - sin a veces darnos cuenta - en particulares condiciones: consumimos movidos por la necesidad (no hay otra alternativa que consumir, al menos en las llamadas necesidades básicas). En apretada síntesis, en consumir nos va la vida —nos procuramos los alimentos imprescindibles para nuestra subsistencia-, ponemos en juego la salud y la integridad fisica - utilizamos bienes y servicios que, creemos, no nos resultarán perjudiciales - y en función de la modalidad y alcances del consumo se determina nuestra calidad de vida y dignidad.

\footnotetext{
"Entiéndase que, sin los consumidores, la producción de los empresarios cae al vacío, y más aún, sus expectativas de lucro; por ende, es necesario mantener firme la estructura del mercado de la manera más equitativa posible, pero no hacer que el consumidor sufra la condición de único sostén. Esta debe ser la meta a tener en cuenta por las aplicaciones que se realizan en el marco de lo que las políticas económicas nacionales denominan dirigismo contractual". (Ver Marcelo Alejandro David. "Defensa de los consumidores y usuarios en el Derecho Nacional (Primera Parte). Origen, y evolución social y legal del derecho de los consumidores y usuarios". Suplemento de Derecho del Consumidor de El Dial, 3 de marzo de 2006).
} 
Nuestra situación se agrava aún más si caemos en la cuenta que realizamos como consumidores un acto de confianza máxima, al adquirir bienes o contratar y utilizar servicios: ${ }^{5}$ ignoramos calidades, formas de producción, composición de materiales, modos de uso, cuidados, efectos, vidas útiles, cómo manipular, cómo mantener; ${ }^{6}$ en suma: nada sabemos respecto de la aptitud del producto o servicio o de su carácter presuntamente inocuo para nuestra salud o seguridad. Frente a nosotros, tenemos a un experto profesional en la materia: el proveedor.

Esta situación de campo caracteriza a la posición del consumidor frente a la relación de consumo como la de la parte más vulnerable de la misma (situación de débil jurídico). A tal desigualdad natural se propicia corregirla mediante desigualdades jurídicas, inclinando el derecho para el lado contrario de la realidad, lo cual converge en la formulación del derecho de consumo como derecho tuitivo o protectorio.

Y esa es la finalidad del régimen tuitivo consumidor, desde su propia configuración en defensa de los consumidores y usuarios y sobre los que la Corte Suprema de Justicia Argentina ha dicho: "Según se desprende de los antecedentes parlamentarios [la Ley No 24.240 de Defensa del Consumidor], tuvo por fin llenar un vacío existente en la legislación argentina, pues otorga una mayor protección a la parte más débil en las relaciones comerciales —los consumidores - recomponiendo, con un sentido ético de justicia y de solidaridad social, el equilibrio que deben tener los vínculos entre comerciantes y usuarios, que se veían afectados ante las situaciones abusivas que se presentaban en la vida cotidiana".

5 “...el ciudadano común que accede a un vagón de subterráneos tiene una confianza fundada en que el organizador se ha ocupado razonablemente de su seguridad. Ello es así porque la prestación de servicios masivos presenta un grado de complejidad y anonimato que resultan abrumadores para quienes los reciben". Del voto mayoritario en autos "Ledesma, María Leonor v. Metrovías S.A." (CSJN; Fallos 331:819).

“...ciudadano común que accede a un vagón de subterráneos tiene una confianza fundada en que el organizador se ha ocupado razonablemente de su seguridad. Ello es así porque la prestación de servicios masivos presenta un grado de complejidad y anonimato que resultan abrumadores para quienes los reciben. El funcionamiento regular, el respaldo de las marcas y del Estado es lo que genera una apariencia jurídica que simplifican y los hacen posibles...", y sostuvo que "El fortalecimiento de la apariencia jurídica y de la confianza son esenciales para estos sistemas, que no podrían subsistir tanto si se negara protección jurídica a las marcas, como si se exigiera que el consumidor se comportara como un contratante experto que exigiera pruebas e información antes de usar el servicio".

6 "...el consumidor es una persona que se encuentra obligada a entablar una relación de consumo para poder satisfacer sus necesidades primarias y secundarias, y normalmente desconoce los derechos y deberes que le competen, las prácticas y técnicas del comercio, así como también las cualidades y costos de fabricación de los productos o servicios". Maronna, Nadia Y. "Prescripción en La Ley de Defensa del Consumidor Publicado: APC 2010-8-833". Citar Abeledo Perrot No: 0003/70062900-1.

7 CSJN, 11/12/2001, Flores Automotores, La Ley Online. Decisorio del Alto Tribunal citado en el precedente de la Cámara de Apelaciones Contencioso, Administrativo y Tributario. Causa Nro.: RDC 587-0. Autos: Públicom S.A. cl G.C.B.A. s/ Otras causas con trámite directo ante la Cámara de Apelaciones. Sala I. Del voto del Dr. Carlos F. Balbín con adhesión del Dr. Esteban Centanaro y Dr. Horacio G. Corti. 12-05-2005. Sentencia Nro. 55. 
Tal es la situación del consumidor, individual y grupal. ${ }^{8}$ No debe confundirse la noción de débil jurídico con la de un interdicto o sujeto que necesita solo protección o asistencialismo, ni con la de ciudadano como la categoría de mero centro de imputación de normas, titular de derechos abstractos que se concretan en contadas ocasiones. Hoy, la concepción de consumidor es más englobante que la de trabajador o de ciudadano. La propuesta -o lo que quizás sea lo mismo, el desafío- es una noción de consumidor que se proyecte hacia el futuro con una matriz superadora, que se construye sobre la base de una normativa que apunte a un consumidor protegido, pero además informado, activo, participante de los procesos e instituciones de decisión acerca de su problemática, y fundamentalmente, dotado de acceso irrestricto a la justicia.

\section{NATURALEZA COMPARTIDA}

\section{A. Categorías históricas y oponibilidad frente al Estado}

El Dr. Pablo Manili" cita a Prieto Sanchís, donde afirma que "los derechos humanos, como categoría ética, cultural e histórica —es decir, prenormativa-, no constituyen una concepción cerrada y acabada de la que puedan beber los ordenamientos positivos, sino un concepto abierto a distintas concepciones y desarrollos y, en consecuencia, no existe una formulación canónica, ni una forma exclusiva de respetar las exigencias que derivan de tales derechos. Tampoco es posible emprender la tarea de comprensión desde un punto de vista externo a la historia”. Así las cosas, la consideración del tema es inescindible del momento histórico en que aparece y en el que se desarrolla.

Los derechos del consumidor, al igual que los derechos humanos, tuvieron origen en la necesidad de hacer valer el respeto a la persona frente al creciente poder del Estado y del mercado, en la creencia efectiva y con base fáctica que de no oponerse derechos fundamentales a esos factores de poder, la debilidad del ciudadano aislado se transforma en indefensión y abandono.

Mientras la ciencia jurídica avanza con la incorporación de los derechos humanos como preocupación y objeto de estudio, las formas de vulnerarlos y desnaturalizarlos se diversifican, se hacen más sutiles. El progreso técnico-científico y el desarrollo industrial amenazan destruir el planeta en que habitamos, lo cual motiva el surgimiento de la formulación de un derecho al medio ambiente sano y su correlato de un consumo también sustentable, como veremos más adelante. 8 Los consumidores y usuarios no representan un grupo determinado como son los trabajadores, sino más bien se presentan
como una masa heterogénea y diseminada, con múltiples problemáticas y muchas veces pocas conexiones.

9 Pablo Manili. "La difícil tarea de elaborar un concepto de los derechos humanos". Revista Jurídica de la UCES, 1 (1999). 
La aparente consolidación del capitalismo y el mercado mostraron el fenómeno de la situación de ciertos actores forzosos del segundo, los consumidores, inermes ante la situación de tener que satisfacer sus necesidades impostergables de bienes y servicios según los dictados, precios y condiciones que fijan los poderosos.

El consumo es una dimensión esencial del ser humano, que involucra derechos fundamentales que deben ser protegidos por el Estado, de ahí que deba prodigarse al consumo también una tutela de la más alta jerarquía como son los derechos humanos, de los que además concuerda con sus caracteres.

\section{B. Caracteres comunes}

Los derechos humanos y el derecho del consumo forman parte de un mismo sistema y son interdependientes, compartiendo un común fundamento (la dignidad humana) y caracteres esenciales.

Los derechos humanos y los derechos de consumidores son consecuencia de la entrada del hombre en sociedad y están en continuo proceso de creación enriqueciéndose con los cambios históricos y dependiendo al mismo tiempo de ellos. Adviértase cómo en los pocos años que lleva de desarrollo el derecho del consumidor hubo de receptar la contratación masiva, el comercio electrónico, la problemática ambiental, y los nuevos consumos en general derivados de las innovaciones tecnológicas (por ejemplo la telefonía celular y la informática) y las modalidades contractuales de esos nuevos servicios, afrontar la cuestión de los datos personales involucrados en la relación de consumo, y más recientemente, temas tales como el sobreendeudamiento de los consumidores y el crédito al consumo, por lo que su catálogo, al igual que el de los derechos humanos, no es en absoluto definitivo, sino que presenta plenamente un carácter expansivo en grado progresivo.

Del mismo modo que los demás derechos humanos, los derechos del consumidor son una formulación ética fundamental y no pueden ser infringidos justificadamente y tienen que ser satisfechos sin ninguna excepción.

Los derechos de consumidores y usuarios se adquieren por ser persona, sin la necesidad de concurrencia de ninguna otra circunstancia.

Pueden tener dimensión económica, pero, como los demás derechos humanos, no pueden ser reducidos a una mera valoración desde esa óptica.

Los valores y derechos protegidos en la relación de consumo son irrenunciables, ya que pertenecen a la persona humana al margen de su consentimiento y le son atribuidos de forma ineludible. El Estado reconoce, respeta y garantiza el respeto a los mismos a partir de su poder normativo de orden público. 
Así como en derechos humanos, el ejercicio de los derechos guarda conexiones entre sí (v.gr. la libertad de culto está relacionada con la libertad de expresión), de la misma forma en el derecho del consumo están involucradas las distintas potestades que no pueden verse separadamente (el derecho a la información se vincula con la salud y seguridad, el de libre elección con protección de intereses económicos, etc.).

Como los derechos humanos, los derechos del consumo son tendencialmente universales, verificándose este carácter en la propensión a incluirlos en los tratados de integración, en el esfuerzo de organismos internacionales en impulsarlos mediante criterios generales que impulsen su desarrollo en los Estados (Directrices de las Naciones Unidas) y el camino hacia la unificación de las directivas nacionales, sin perjuicio de las realidades culturales propias que muestran determinadas pautas y objetos de consumo características de comunidades especificas.

Los derechos humanos y los de consumidores y usuarios tienen el mismo tratamiento legal con base en los principios de igualdad ante la ley, no discriminación, desarrollo progresivo y protección del medio ambiente.

Las garantías que resguardan su ejercicio deben ser eficaces e inmediatas en su finalidad.

\section{Criterio de interpretación común}

En cuanto a los principios interpretativos, los derechos del consumidor como especie de los derechos humanos deben ser y son interpretados en el sentido de acudir a la norma más amplia cuando se trate de protección y a la norma más estricta cuando se trate de restricciones a los derechos (arts. 29 y 30 de la Convención Americana de Derechos Humanos).

\section{Sujetos protegidos}

Casi no hay obra o artículo que no incluya la frase de John F. Kennedy respecto a que todos somos consumidores. ${ }^{10}$ Un concepto tan amplio, tan generalizado, muchas veces ve socavada su importancia en su misma generalidad. Consumir es algo tan normal, tan de todos los días, ${ }^{11}$ que parece haber existido siempre, y lamentablemente muchas veces es solo merecedor como fenómeno- de análisis compartimentados, en una deformación de la tendencia a la especialización propia de los tiempos que corren.

10 Frase extractada del mensaje de elevación presidencial al Congreso del primer paquete de leyes relativas a la protección del consumidor en los Estados Unidos, generadas en la década del sesenta a partir del desastre de la comercialización de la talidomida, droga para embarazadas que fue célebre por las malformaciones causadas, y que desató la conciencia de la necesidad de legislar sobre consumo, a partir de la responsabilidad por productos elaborados. Producto genuino de estos tiempos de globalización, este acontecimiento doméstico norteamericano genera el establecimiento del día mundial del consumidor.

11 Sin lugar a dudas, el derecho del consumidor es el más cotidiano de todas las ramas del Derecho. Piénsese en la cantidad de actos de consumo que realiza el ciudadano "medio" en su jornada diaria, y se verá que no hay actos jurídicos más frecuentes e indispensables que los que al consumidor respectan. 
La tendencia legislativa en el Derecho Argentino y comparado ha sido claramente la de ampliar el espectro de consumidores y usuarios para así expandir el ámbito de protección tutelar. Es decir, se desdibuja de esta forma el concepto clásico y acotado de "consumidor" que originariamente solo incluía la contratación a título oneroso, eliminándose ese distingo legal resultando indiferente para la configuración de la relación de consumo la gratuidad del vínculo, y abarcando, como en el caso argentino a "quien no es parte de una relación de consumo pero como consecuencia o en ocasión de ella adquiere o utiliza bienes o servicios y a quien de cualquier manera este expuesto a una relación de consumo" (Art. 1 Ley 24.240).

Obsérvese también que, entre otros aspectos, muchos ordenamientos protegen a las empresas que adquieran bienes y servicios, que también serán alcanzadas por la protección de la ley en la medida que no los integran como insumos directos a otros bienes y servicios a ser comercializados. ${ }^{12}$ Este dato no obsta al carácter de derecho humano de los derechos del consumidor, toda vez que las personas jurídicas son indiscutiblemente sujetos de derechos que también son derechos humanos (v. gr. el derecho a la propiedad), y va de suyo que esa titularidad no les da humanidad ni carácter de sujetos de derechos humanos.

\section{PREVIAMENTE A ENTABLARSE LA RELACIÓN CON EL PROVEEDOR, EL ACCESO AL CONSUMO ES TAMBIÉN UN DERECHO HUMANO}

Como aspecto previo a entablar la relación de consumo (previo a su concreción), el acceso al consumo, como derecho, está comprendido dentro de las Directrices de las Naciones Unidas para la Protección del Consumidor (1985 y modificaciones), y presente en forma implícita en distintos artículos de la ley 24.240, que no refiere este aspecto con la misma denominación, sino que hay que indagarlo en su espíritu. Constitucionalmente, interpretamos que en el caso argentino se encuentra consagrado al establecerse en forma expresa el derecho al trato equitativo y digno (párrafo primero del artículo $42 \mathrm{CN}^{13}$ ), aspecto que se extiende a los supuestos en que la relación de consumo ya se encuentra entablada.

En el MERCOSUR, los derechos del consumidor y el usuario resultan de la Resolución no 124/96 del Grupo Mercado Común del 13 de diciembre de 1996 sobre Derechos

12 Cámara de Apelaciones Contencioso, Administrativo y Tributario de la Ciudad Autónoma de Buenos Aires, Causa Nro.: 2395-0. Autos: "Establecimiento Yanovsky Hnos. SRL c/ GCBA s/ Otras causas con tramite directo ante la Cámara de Apelaciones". Sala II. Del voto de la Dra. Nélida M. Daniele con adhesión del Dr. Esteban Centanaro, del 04-05-2010. Sentencia Nro. 35.

13 Artículo No 42 de la Constitución Nacional Argentina. Los consumidores y usuarios de bienes y servicios tienen derecho, en la relación de consumo, a la protección de su salud, seguridad e intereses económicos; a una información adecuada y veraz; a la libertad de elección, y a condiciones de trato equitativo y digno. Las autoridades proveerán a la protección de esos derechos, a la educación para el consumo, a la defensa de la competencia contra toda forma de distorsión de los mercados, al control de los monopolios naturales y legales, al de la calidad y eficiencia de los servicios públicos, y a la constitución de asociaciones de consumidores y de usuarios. La legislación establecerá procedimientos eficaces para la prevención y solución de conflictos, y los marcos regulatorios de los servicios públicos de competencia nacional, previendo la necesaria participación de las asociaciones de consumidores y usuarios y de las provincias interesadas, en los organismos de control. 
Básicos del Consumidor y de la Declaración Presidencial de Derechos Fundamentales de los Consumidores del MERCOSUR de Florianópolis, del 15 de diciembre de 2000. Ambos textos reconocen los derechos a la vida, la salud y la seguridad; a la libertad de acceso al consumo; a la información suficiente y veraz; a la protección contra la publicidad no permitida; a la adecuada prestación de servicios públicos y privados; a la educación para el consumo; a la asociación en organizaciones que tengan por objeto la defensa del consumidor; al acceso a la justicia "mediante procedimientos ágiles y eficaces"; a la prevención y al resarcimiento de daños. ${ }^{14}$

Acceso al consumo significa que la posibilidad de llegar a consumir debe extenderse a todos los sectores de la población. En esta etapa no se analiza la capacidad económica para hacerlo (las posibilidades materiales de consumir son estudiadas por la economía, en primer término, y determinadas por la política), sino que visto desde su faceta de derecho humano, el derecho de acceso al consumo involucra los siguientes aspectos:

- El trato equitativo y digno es consagrado por la normativa constitucional, sin distinciones y sin discriminación alguna. Dignidad significa trato justo en la relación de consumo, con respeto a la vida, salud, e integridad física de las personas. ${ }^{15}$

- Acceso al consumo para todos se vincula indisolublemente con el principio de no discriminación, siendo este aspecto característico de la condición de derecho humano del derecho del consumidor, e importa existencia de infraestructura, medios e información para colocar al consumo al alcance y a la comprensión de todos los sectores de la población, e introduce la problemática de los sectores con necesidades especiales o características diferentes (ancianos, niños, discapacitados, personas de bajo nivel cultural, etcétera) en derechos fundamentales como el que nos ocupa.

- La serie de derechos que contiene el artículo 42 de la Constitución Argentina presuponen la existencia del derecho de acceso al consumo, de modo que este resulta un derecho implícito en toda la formulación de dicha norma.

- Al basarse el nuevo modelo de Estado diseñado por la Constitución en 1994 en el eje del desarrollo económico y social, y en los principios del desarrollo sustentable, está determinando un piso por debajo del cual se entienden violados los derechos del artículo 42. En esta inteligencia "si un habitante no tiene acceso al consumo en lo que hace a sus necesidades básicas, se está incumpliendo con uno de los requisitos del desarrollo sustentable: la sustentabilidad social". ${ }^{16}$

${ }_{14}$ Atilio Aníbal Alterini. "Las reformas a la ley de defensa del consumidor. Primera lectura, 20 años después”. La Ley, 1 (2008).

15 "Todo ser humano tiene frente a cualquier otro el derecho a ser respetado como persona, a no ser perjudicado en su existencia y en un ámbito propio del mismo, y cada individuo está obligado frente a cualquier otro de modo análogo". (Mosset Iturraspe y Lorenzetti. Defensa del Consumidor Ley 24.240. Buenos Aires: Rubinzal Culzoni, p.11).

16 Laura Pérez Bustamante. Derecho Social de Consumo. Buenos Aires: La Ley, 2004, p. 100. 
- Un principio de equidad generacional e internacional hace que tanto la pobreza (falta de acceso al consumo) como el consumismo (uso indiscriminado de los recursos) sean contrarios a la Constitución, por no compadecerse con el paradigma de desarrollo que esta consagra.

- En esta línea de pensamiento, si bien la medida del acceso al consumo está marcada "por las particularidades de cada momento histórico (nivel de evolución del desarrollo, valoraciones sociales, etcétera), tales circunstancias fácticas no obstan a la existencia del derecho de acceso al consumo como derecho subjetivo." 17

- En suma, se trata del derecho de acceder a un nivel de consumo compatible con el desarrollo sustentable que los poderes públicos tienen la obligación de hacer efectivo, y que — como señalaré seguidamente- es operativo y exigible judicialmente, dado que "la consecuente postura de la no judiciabilidad de las cuestiones relativas a la distribución de recursos estatales — presupuesto-, pierde su justificación con el nuevo orden constitucional y el sistema de desarrollo en él previsto." ${ }^{18}$ Es un deber del Estado promover la inclusión social, con especial preocupación por los sectores más vulnerables, al menos para el logro de condiciones mínimas que permitan el ejercicio de la autonomía individual, la toma de decisiones de vida.

- La obligación de los Estados es, entonces, respetar, proteger, garantizar y cumplir. En el vasto espectro de la protección de los derechos del consumidor como derecho humano, las acciones estatales en salvaguarda de este derecho deben ser analizadas en el marco de la interdependencia que existe entre los derechos humanos, la democracia y el desarrollo económico, "pues tampoco se puede desconocer la existencia de condiciones objetivas que en sí mismas constituyen una violación de la dignidad humana, y que hacen indispensable realizar esfuerzos que permitan erradicar la pobreza extrema y eliminar la injusticia social". ${ }^{19}$ Todo ello sin dejar de tener en cuenta un dato de la realidad: si bien desde lo jurídico el Estado sigue siendo el responsable internacionalmente de toda violación a los derechos humanos, muchas veces en la práctica se verifica que este se retira o sucumbe frente al poder real de las fuerzas del mercado y esa falencia puede corregirse en el Derecho interno mediante la puesta en marcha de los mecanismos del sistema y cierto sano protagonismo judicial.

17 Ibid., p.101.

18 Ibid.

19 Héctor Faúndez Ledesma. El sistema interamericano de protección de los derechos humanos. Aspectos institucionales y procesales. Tercera edición. Costa Rica: Instituto Interamericano de Derechos Humanos, 2004, p. 6. 


\section{EL CONCEPTO DE PERSONA Y EL CONCEPTO DE CONSUMIDOR}

El surgimiento de la noción y rol de consumidor como sujeto de derecho implica la superación de la noción abstracta de persona del Código Civil (ente susceptible de adquirir derechos y contraer obligaciones) y en particular de persona física (aquellas que presentan signos característicos de humanidad) para dar paso a la visión humanista que impregna el estudio del fenómeno del consumo dentro de la ciencia del derecho, propia de los derechos humanos.

Persona (consumidor) es todo ser humano en toda la amplitud y significación de ese concepto. ${ }^{20}$ Amplitud porque no excluye a nadie. Y significación por cuanto la noción humanista de consumidor engloba al sujeto de los mismos, no en abstracto, sino en un medio y en una situación determinada (ya descrita al analizar la posición de débil jurídico), presupuesta por el legislador y orientada hacia el ejercicio efectivo de los derechos.

Esto implica ver por una óptica diferente, distinta también al del tradicional Derecho Comercial, el fenómeno de la contratación mercantil cuya función social e importancia es fundamental para la satisfacción de las necesidades materiales, espirituales, científicas y de esparcimiento del hombre, para las que "recurre a las empresas productoras y distribuidoras de los bienes y servicios que se lanzan al mercado a dicho fin" ${ }^{21}$ En igual carácter, Mosset Iturraspe y Lorenzetti ${ }^{22}$ mencionan que la filosofía básica del derecho del consumidor es justamente superadora de la tradicional visión que parte de sujetos económicamente iguales, con poder de negociación similar, para reemplazarla por la de consumidor como ser necesitado, sujeto pasivo del consumo y receptor o destinatario principal de esta actividad.

El derecho del consumidor es un conglomerado de valores preferentes que entiende al consumidor como persona en el mercado y, por lo tanto, eje de todo el sistema jurídico y económico, el sujeto principal de protección, a través de la fijación de estándares básicos.

\section{EL MEDIO AMBIENTE SANO Y APTO PARA EL DESARROLLO HUMANO ES INTERDEPENDIENTE CON UN CONSUMO QUE GARANTICE LA SUSTENTABILIDAD}

Desarrollo sustentable y consumo sustentable se implican mutuamente.

En líneas generales, el desarrollo sustentable:

- Satisface necesidades del presente, sin comprometer a generaciones futuras.

- Pone al ser humano como centro y razón de ser del desarrollo.

20 El Pacto de San José de Costa Rica expresa claramente que a los efectos de esa Convención, persona es “todo ser humano" (art. 4).

${ }^{21}$ Juan M. Farina. Defensa del consumidor y del usuario. Buenos Aires: Astrea, 2004, p. 1.

22 Defensa del Consumidor. Ley 24.240. Rubinzal-Culzoni Editores, p. 20 y ss. 
En los múltiples aspectos de su cosmovisión, los conceptos vinculados de desarrollo y consumo sustentable se asocian con las características de un desarrollo que además sea:

- Políticamente sustentable, a través de la profundización de la democracia.

- Culturalmente sustentable, a través de la preservación de la diversidad de valores.

El concepto de desarrollo que se hermana con la noción de consumo sustentable es el elaborado por la Organización de las Naciones Unidas, en una formulación que ayuda a desvincular la noción de progreso solamente asociada a aspectos materiales, y a la vez desvincular mentalmente el prejuicio hacia la preocupación ambiental que la relaciona con la negativa reaccionaria a la industrialización y con una significación de atraso.

Desarrollo humano no es anticrecimiento. No solo tiene que ver con la distribución de la riqueza, sino también con su creación. Desde una perspectiva más amplia y concreta que los conceptos anteriores de desarrollo (es decir, los enfoques que concedían atención exclusiva al crecimiento económico), demuestra que este, si bien es vital, no basta (por sí) para el mejoramiento de la vida de las personas. El crecimiento no es el fin del desarrollo humano, sino un medio. Ambos están estrechamente ligados: "las personas contribuyen al crecimiento, y el crecimiento contribuye al bienestar humano"; 23 así, el uso de servicios y productos relacionados que responden a las necesidades básicas y conllevan una mejor calidad de vida debe realizarse minimizando el uso de recursos naturales y materiales tóxicos así como también la emisión de residuos y contaminantes sobre el ciclo de vida, de tal forma que no haga peligrar las necesidades de las generaciones futuras. ${ }^{24}$

Señala con acierto López Alfonsín que "los derechos humanos de tercera generación han sido consagrados para corregir las graves injusticias de la humanidad” y están concebidos para pueblos, grupos sociales e individuos (derechos de la solidaridad), en una nueva concepción de "Estado social, económico y ambiental de Derecho". ${ }^{25}$

\section{LAS NORMAS DE DERECHO DE CONSUMIDORES Y USUARIOS SON OPERATIVAS Y DIRECTAMENTE APLICABLES}

Las normas operativas son aquellas inmediatamente aplicables, autoejecutivas (selfexecuting en el Derecho Norteamericano), cuya aplicabilidad es directa en sede judicial, y que son la regla de las contenidas en el orden jurídico constitucional argentino y en los tratados internacionales de derechos humanos a este incorporados.

23 Informe de 1992 del Programa de Naciones Unidas Para el Desarrollo.

24 Definición adoptada por la Comisión de Naciones Unidas para el Desarrollo Sustentable, 1995

${ }^{25}$ Marcelo López Alfonsín. Derecho Ambiental. Buenos Aires: Astrea, 2012, p. 13. 
Por otro lado, las llamadas programáticas son aquellas que en su propio texto o formulación fijan directivas para el dictado de otras normas que permitan su aplicación. De ahí su denominación, ya que se limitan a fijar un "programa" de seguimiento obligatorio por el Estado legislador, que se obliga a dictar las normas que hagan efectivo y aplicable el derecho en cuestión. El Estado se obliga al dictado de la norma que la misma norma manda dictar.

El principio constitucional, como lo tiene dicho la Corte Suprema Argentina a partir de los fallos Siri y Kot ${ }^{26}$ es que las garantías constitucionales son directamente operativas y el juzgador debe suplir las omisiones del legislador otorgando la protección en el caso concreto que se lleva a su decisión. Este criterio se dejó de lado en algunos supuestos posteriores, para volver a ser implementado después de la reforma de 1994, con relación a la operatividad del Pacto de San José de Costa Rica o Convención Americana de Derechos Humanos. ${ }^{27}$

La operatividad de las normas puede y debe ser dada por el magistrado, con el alcance de las decisiones judiciales ya que "de nada valdría la incorporación constitucional de los nuevos derechos y garantías si hubiera que esperar a la ley o quedar supeditada a ella”. ${ }^{28}$

Debe atenderse fundamentalmente a que en derechos humanos se presume que las normas en la materia son operativas. Y al participar de los caracteres de los derechos humanos, en el caso de las normas de consumo, se trata de dispositivos clara y directamente atinentes, y no existe impedimento alguno para su aplicación inmediata. ${ }^{29}$ Eso sucede no solo por su formulación sino esencialmente por "la naturaleza del derecho que protege, que no es otro que un derecho humano". ${ }^{30}$

La jurisprudencia nacional ha dicho: “...la norma del Artículo 42 de la Constitución Nacional pone en cabeza de los consumidores y usuarios derechos plenos, los cuales son operativos sin necesidad de que se dicte una ley que los instrumente, lo que significa que el juez puede aplicarlo en el caso concreto y que su eficacia no está condicionada...". ${ }^{31}$

26 La Ley, 89-531; 92-632.

27 Fallos 308:647.

28 Ver, además, José Luis Correa. "Acciones de incidencia colectiva. Modificación de La Ley de Defensa del Consumidor”. La Ley (2008-F), 1106.

29 Cfr. Jorge Mario Galdós. "La relación de consumo en la jurisprudencia de la Corte Suprema de Justicia de la Nación”. En Ley de Defensa del Consumidor. Comentada y anotada, Vázquez Ferreyra y Picasso Directores. Buenos Aires: La Ley, 2011, tomo III, pp. 33 y ss., con cita de plurales antecedentes de la C.S.J.N. ("Bianchi”, "Mosca", "Ledesma", "Uriarte", "Halabi”) en tal sentido. Citado por Villaragut Marcelo, Calderón Maximiliano Rafael. "El beneficio de gratuidad de La Ley de Defensa del Consumidor en la jurisprudencia de las Cámaras de Apelaciones de Córdoba”. LLC (noviembre de 2011), 1047.

30 Ver Esteban Javier Arias Cau; Guillermo M. Vera Mohorade. "Participación de las asociaciones de consumidores en los organismos de control de servicios públicos". LLNOA, (2011), p. 235.

31 Ricardo Luis Lorenzetti. Consumidores. Santa Fe: Rubinzal-Culzoni, 2003, pp. 44-45. 
La Ley de Defensa del Consumidor es una norma de raigambre constitucional y obligatoria, al igual que la acción de defensa del usuario y del consumidor tal como surge de la misma, que es de orden público. La Corte Suprema de Justicia ha resuelto “... que las normas constitucionales que reconocen la existencia del derecho del consumo son operativas per se, independientemente de que el Congreso o el Poder Ejecutivo hayan dictado regulaciones específicas". ${ }^{32}$

$Y$ en igual sentido:

"El citado artículo 42 tiene una doble proyección: el derecho de los usuarios y consumidores a la protección de sus intereses personales y económicos, y el correlativo deber del Estado de asegurarlos; deber que es también exigible a los proveedores de bienes y servicios ${ }^{33}$. Estas garantías son operativas y no dependen de su reglamentación atento a su naturaleza y a la vía judicial que se prevé expresamente en el artículo 43 de la Constitución". ${ }^{34}$

"El ap. $2^{\circ}$ del artículo $42, \mathrm{CN}$ es una norma operativa, y si bien no dice que las autoridades proveerán a la protección de esos derechos es porque los derechos ya están acordados y como tales - merecen la tutela operativa del artículo 43 ". ${ }^{35}$

"La Ley de Defensa del Consumidor 24.240 consagra la protección de los intereses económicos de consumidores y usuarios, otorgándoles derecho a una información adecuada y condiciones de trato equitativo y justo, con explícita base constitucional —artículo 42, $\mathrm{CN}-$, y con alcance operativo e inmediato principio de cumplimiento". ${ }^{36}$

“... La norma del artículo 42 de la Constitución Nacional pone en cabeza de los consumidores y usuarios plenos derechos, los cuales son operativos sin necesidad de que se dicte una ley que los instrumente" ${ }^{37}$

32 Voto del Dr. Lorenzetti. Ministerio de Salud y/o Gobernación. Corte Suprema de Justicia de la Nación, Fallos: 329 : 4741.

33 Cfr. Germán Bidart Campos. Tratado Elemental de Derecho Constitucional. Tomo VI, pp. 308-309; Abel Fleitas Ortiz de Rozas. "La protección del usuario". Ponencia realizada en las Jornadas Jurídicas sobre Servicio Público de Electricidad, el 8 y 9 de junio de 1995.

34 Fallos 322:1941, citado por Paola Cabezas Cescato. “Acerca del artículo 42 de la Constitución Nacional”. La Ley (1999E), p. 211.

35 Juzgado Nacional de Primera Instancia en lo Civil Nro. 54, publicado en JA 2000-III-síntesis.

36 Cámara Nacional de Apelaciones en lo Comercial, sala B, publicado en LL 1999-E-717; DJ 1999-3-840.

37 Cámara Federal en lo Contencioso Administrativo, sala II, "Ciancio José C. ENARGAS", del 5/11/98, publicado en La Ley 1999-B, 526. 


\section{LAS GARANTÍAS EN EL DERECHO DEL CONSUMO DEBEN SATISFACER EL REQUISITO DE EFICACIA EXIGIDO PARA LA PROTECCIÓN DE LOS DERECHOS HUMANOS}

El derecho del consumidor, por su propia naturaleza de derecho humano, requiere mecanismos y procedimientos que atiendan adecuadamente las situaciones que se producen y que a veces no encuentran solución en los sistemas tradicionales. Estos a su vez tienen que cumplir con el requisito de eficacia, ${ }^{38}$ que implica la posibilidad de obtener una respuesta del sistema a los reclamos del consumidor en tiempo, modo y condiciones de acceso que no desnaturalicen la protección de los derechos.

Tenemos por acertada la expresión que reza "si no hay garantías no hay derechos" o que "los derechos son lo que las garantías quieren que sean". La existencia de instrumentos efectivos para la defensa de los derechos hace a su plena vigencia y ejercicio. Sin estos, los derechos constitucionales serían un auténtico catálogo de ilusiones.

Esto no es solo una afirmación dogmática sino imperativa para el legislador y para el magistrado. La función estatal en la materia tiene este carácter a nivel universal. Corresponde a las leyes dar las precisiones y a los magistrados las aplicaciones.

Las Directrices para la Defensa del Consumidor de las Naciones Unidas (1985) establecen que los gobiernos de los Estados miembros deben desarrollar políticas enérgicas de protección del consumidor (artículo 2) y diseñar infraestructuras adecuadas para aplicarlas (artículo 4).

En el caso argentino, la Ley Nacional 24.240 (y modificatorias) de Defensa del Consumidor, en concordancia con otras normas complementarias y reglamentarias, ha determinado las características del sistema de soluciones para la satisfacción de los derechos de los consumidores, en las materias de fondo de competencia nacional (contratos, daños y perjuicios, garantías, deberes y responsabilidades de los proveedores), siendo atribución local de las entidades componentes del Estado federal el establecimiento de los llamados "derechos instrumentales", que hacen a la implementación de la protección, destinada a permitir a los consumidores hacer valer en lo concreto, en forma real y efectiva, los derechos que la ley les otorga y el debido resguardo de los bienes jurídicos protegidos y valores comprendidos en la legislación de fondo. La eficacia protectoria se encuentra en relación directa con el mismo carácter de la normativa destinada a afirmar su vigencia.

38 En algunos tipos de servicios, la eficacia en materia temporal resulta determinante para la protección de los derechos, como es el caso de los servicios turísticos, donde el denunciante permanece pocos días en el lugar de los hechos, y por ende en el ámbito geográfico donde debe reclamar. Algunos países han establecido tribunales arbitrales para cuestiones turísticas, con procedimientos sencillos y rápidos (Benidorm, España). 
En términos de derechos humanos, la imperativa existencia de recursos adecuados y eficaces para la defensa de los derechos se define y se conforma con la certidumbre y presencia de mecanismos judiciales que den solución al caso en tiempo y forma, para el arribo a una sentencia o resolución definitiva con lo que en un primer dato tendremos a la celeridad como presupuesto de la eficacia. ${ }^{39}$

Esa eficacia hace que también los recursos sean sencillos y efectivos, es decir, que tengan potencial para determinar si existe en el caso violación o afectación a un derecho, y disponer lo necesario para su cese, sanción y reparación.

Por eso, las garantías acordes a la interpretación de los tribunales supranacionales del Sistema Interamericano de Protección de los Derechos Humanos son aquellas que son idóneas, dentro del Derecho Interno, para atender la situación jurídica infringida, y que, sobre todo, produzcan el resultado para el cual han sido concebidas. ${ }^{40}$

Finalmente, señalamos que bien puede ser considerada una de las características relacionadas con la eficacia, el hecho de que haya sido reconocida en el caso argentino, la legitimación activa para acciones de consumo y por la propia Constitución Nacional ${ }^{41}$ a órganos con competencia en la defensa de los derechos humanos como el Defensor del Pueblo. ${ }^{42}$

El derecho a la "tutela judicial efectiva" ${ }^{33}$ tiene naturaleza supranacional, y se encuentra contemplado en los artículos 8 inc. 1 y artículo 25 del Pacto de San José de Costa Rica, que ha sido uno de los tratados a los que se les atribuyera jerarquía constitucional por el artículo 75 inc. 22 en la Reforma de 1994.

39 Comisión Interamericana de Derechos Humanos. Informe Nro. 35/98: Caso 11.760, Manuel Aguirre Roca, Guillermo Rey Terry y Delia Revoredo de Mur, Perú, 5/5/98.

40 Corte I.D.H., Caso de la Comunidad Mayagna (Sumo) Awas Tingni. Sentencia de 31 de agosto de 2001. Serie C No. 79, párrafo 111; Caso Cantos. Sentencia de 28 de noviembre de 2002. Serie C No. 97, párrafo 52; Caso Juan Humberto Sánchez. Sentencia de 7 de junio de 2003. Serie C No. 99, párrafo 121; Caso Maritza Urrutia. Sentencia de 27 de noviembre de 2003. Serie C No. 103, párrafo 117, entre otros.

41 Artículo 43. Constitución Argentina (parte pertinente): “Toda persona puede interponer acción expedita y rápida de amparo, siempre que no exista otro medio judicial más idóneo, contra todo acto u omisión de autoridades públicas o de particulares, que en forma actual o inminente lesione, restrinja, altere o amenace, con arbitrariedad o ilegalidad manifiesta, derechos y garantías reconocidos por esta Constitución, un tratado o una ley. En el caso, el juez podrá declarar la inconstitucionalidad de la norma en que se funde el acto u omisión lesiva. Podrán interponer esta acción contra cualquier forma de discriminación y en lo relativo a los derechos que protegen al ambiente, a la competencia, al usuario y al consumidor, así como a los derechos de incidencia colectiva en general, el afectado, el defensor del pueblo y las asociaciones que propendan a esos fines, registradas conforme a la ley, la que determinará los requisitos y formas de su organización".

42 Conforme el artículo 86 de la Constitución Nacional “...su misión es la defensa y protección de los derechos humanos y demás derechos, garantías e intereses tutelados en esta Constitución y las leyes, ante hechos, actos u omisiones de la Administración; y el control del ejercicio de las funciones administrativas públicas".

43 La locución tutela judicial efectiva nace con la redacción del artículo 24 de la Constitución de Italia de 1947 y con la confección de los arts. 19.4 y 103.1 de La Ley fundamental de Bonn de 1949, siendo mayormente conocida por su incorporación al artículo 24 de la Constitución española de 1978 y al artículo 8 de la Convención Americana de Derechos Humanos. 
También las mencionadas Directrices de las Naciones Unidas para la Protección del Consumidor $^{44}$ encomiendan a los gobiernos la existencia de procedimientos "oficiales o extraoficiales que sean rápidos, justos, poco costosos y asequibles”.

De modo que lo que el compromiso asumido al adherir a la normativa internacional vincula tanto respecto a la eficiencia de la justicia como a su acceso irrestricto: implica que se brinden protecciones anticipadas que de no darse harían infructuoso el proceso, que los mecanismos procesales existentes funcionen, y que en la práctica den una solución (efectividad). Esto importa además que se le brinde al consumidor una solución a través de darle la razón a quien la tenga (reconocimiento de derechos) y en el lapso previsto por el legislador (el ya nombrado concepto de eficacia asociado a la celeridad), vinculándose también con que el acceso a la justicia no se vea impedido por causas económicas. ${ }^{45}$

A su vez, el pronunciamiento de mérito debe importar una verdadera satisfacción y reparación de los derechos violados o desconocidos. Como principio práctico de política judicial, requiere magistrados activos y también preventores, que prefieran evitar los problemas antes que deshacerlos, ${ }^{46} \mathrm{o}$ antes que esperar sus manifestaciones y consecuencias.

\section{EL RESARCIMIENTO EN EL DERECHO DEL CONSUMO SE BASA EN LA VIGENCIA DEL PRINCIPIO DE REPARACIÓN INTEGRAL}

El principio alterum non laedere prohíbe a los hombres "dañar los derechos de un tercero, a la justicia social y a la dignidad humana" ${ }^{47}$ En su virtud, rige en materia de derecho del consumidor el principio de reparación integral del daño causado.

Esta conclusión ${ }^{48}$ deviene de un principio general del Derecho: la integridad de la persona humana. En ese razonamiento, lo que pretende el "derecho de daños" es que se mire el daño

44 Las Directrices aprobadas por la Asamblea General de la Organización de las Naciones Unidas en 1985, Resolución 39/248, ampliadas en 1999, enumeran expresamente cuáles son los derechos de los consumidores y usuarios, la obligación de proveer a la protección de los mismos por parte de las autoridades propiciando legislación que reconozca a los mismos y permita su intervención para esos fines. Constituyen "lineamientos para la aplicación de políticas gubernamentales de protección al consumidor", y más allá de su leve rango de Directrices (no son tratados) constituyen postulados de los cuales la legislación interna no puede apartarse.

45 Sostiene Carlos Ghersi que "la iniciación (de acciones judiciales) con gratuidad tiene un fundamento de derechos humanos: ello porque el salario del trabajador-consumidor resulta imprescindible para la provisión de la canasta básica para sí o para su familia y no puede ser sustraído para otra función. Esta es la esencia central de la gratuidad para iniciar las acciones, que solo tiene como finalidad la protección de sus derechos humanos esenciales, es decir, no ser vulnerado por las empresas como trabajador-consumidor". Ver del autor, comentario al fallo "Arroyo Estela María c. Caja de Seguros S.A.” de la Cámara de Apelaciones en lo Civil y Comercial de Córdoba, 15/9/2011 en Microjuris. Cita: MJJ68866.

46 Ver José M. Torres Traba. "Utilidad procesal de las medidas cautelares atípicas. La tutela anticipada de los derechos y la medida innovativa”. En DJ 05/11/2008, 1913; DJ 2008-II, 1913.

47 Corte Suprema de Justicia de la Nación, del 21/09/2004. "Aquino, Isacio c. Cargo Servicios Industriales S.A.”. La Ley, Suplemento Especial (septiembre de 2004), p. 39.

48 Carlos A. Ghersi. "Responsabilidad del Estado. Daños por actos lícitos e ilícitos de sus funcionarios u órganos". La Ley (2011-C), p. 149. 
desde el dañado y no la conducta del agente dañador, es decir, la reparación debe relacionarse con el daño efectivamente causado, y por ello debe ser integral, independientemente de la "cualidad y cantidad" del accionar del agente dañador.

El principio de reparación integral ha sido claramente puesto de manifiesto por la Corte Suprema de Justicia de la Nación en el recordado fallo "Santa Coloma", ${ }^{49}$ donde se expresó que "la sentencia apelada lesiona el principio alterum nom laedere que tiene raíz constitucional (artículo $19 \mathrm{CN}$ ) y ofende el sentido de justicia de la sociedad, cuya vigencia debe ser afianzada por el Tribunal en el marco de sus atribuciones y en consonancia con lo consagrado en la Carta Magna” (considerando séptimo), estableciendo a su vez que este principio tiene jerarquía constitucional con sustento en el artículo 19 CN. Concordantemente, los artículos 1109 y 1113 del Código Civil Argentino consagran el principio general establecido en el artículo 19 de la Constitución Nacional, que prohíbe a los hombres perjudicar los derechos de un tercero y reiterado en los supuestos Gunther ${ }^{50}$ y Luján ${ }^{51}$ del Alto Tribunal.

Más recientemente, este principio de reparación integral tuvo especial consideración en el fallo de la Corte Suprema "Aquino", ${ }^{52}$ donde se reiteró el reconocimiento del estatus constitucional del principio de reparación integral, reglamentando los alcances de la regla elemental alterum non laedere como "un principio general que regula cualquier disciplina jurídica”.

También han entendido los Tribunales ${ }^{53}$ que el derecho a ser reparado posee base constitucional con base en que: a) La reparación de los perjuicios implica una prolongación de la seguridad jurídica, valor ínsito en el ordenamiento fundamental del Estado; b) El derecho a la reparación es la lógica consecuencia de la violación de un derecho; si este está consagrado en la Constitución, también lo está el derecho a su reparación; c) Se trata en definitiva de un desprendimiento conceptual del derecho de propiedad y del valor justicia.

Además, ha sido entendido que el derecho a la reparación se deduciría del primer párrafo del artículo 19 de la Constitución Nacional, o por derivación del derecho de propiedad tutelado por el artículo 17, o directamente de la garantía de la seguridad jurídica. ${ }^{54}$ También ha sido considerado uno de los derechos implícitos en el artículo 33, contenido en los tratados incorporados en el artículo 75 inciso 22 (tratados de derechos humanos).

49 Corte Suprema de Justicia de la Nación. “Santa Coloma Luis c. Ferrocarriles Argentinos”. Fallos: 308:1160

${ }^{50}$ Fallos 308:1118.

51 Fallos 308:1119.

52 Corte Suprema de Justicia de la Nación. “Aquino, Isacio c. Cargo Servicios Industriales S.A.” La Ley, Suplemento especial, (septiembre, 2004), p. 39, donde se estuvo por la inconstitucionalidad de La Ley de Riesgos del Trabajo y su sistema indemnizatorio, distinto del derecho común y limitado en su cuantía.

53 Corte Suprema de Justicia de la Provincia de Buenos Aires. "Britez, Primitivo c. Productos Lipo S.A. Artículo 1113. Daños y perjuicios”, del 6/6/2001. El texto completo puede consultarse en www.abogarte.com.ar/inconstitucionalidadleyriesgotrabajo. html

54 Ver Carlos José Laplacette. “Derecho constitucional a la reparación de daños”. La Ley (setiembre, 2012). 
En el Sistema Interamericano de Protección de los Derechos Humanos, el artículo 63 del Pacto de San José de Costa Rica faculta a la Corte Interamericana de Derechos Humanos a disponer que se reparen las consecuencias de la violación a los derechos humanos a través del pago "de una justa indemnización a la parte lesionada". El tribunal internacional ha clarificado en sus sentencias que el alcance de la reparación ${ }^{55}$ es la plena restitución (restitutio in integrum), que consiste en el restablecimiento de la situación anterior, y de no ser esto posible, cabe al tribunal internacional "determinar una serie de medidas para, además de garantizar los derechos conculcados, reparar las consecuencias que las infracciones produjeron y establecer el pago de una compensación por los daños ocasionados". ${ }^{56}$

\section{CONCLUSIONES}

- Los derechos de usuarios y consumidores son derechos humanos, tanto en la faz de derecho de acceder al consumo, como en la relación consumidor/usuario y proveedor ya entablada.

- En la relación de consumo se encuentran involucrados bienes jurídicos y valores protegidos propios de los derechos humanos como la dignidad, la vida, la salud, etc.

- Del mismo modo que los demás derechos humanos, el surgimiento y desarrollo de los derechos de consumidores y usuarios se comprenden por su contexto histórico, en constante dinamismo.

- Los derechos de usuarios y consumidores son también exigibles frente al Estado, son interdependientes entre sí, y constituyen una categoría ética fundamental basada primariamente en el principio de no discriminación y tomando como punto de partida el concepto de persona propio de los derechos humanos.

- Los usuarios y consumidores adquieren derechos por su condición de persona, en especial en la particular situación de consumir.

- Los derechos de usuarios y consumidores se interpretan aplicando la norma que sea más favorable a los sujetos del derecho y que por ende otorguen la protección mayor.

- El medio ambiente sano y el desarrollo sustentable son interdependientes de la concepción de consumo sustentable.

55 También el tribunal internacional ha utilizado soluciones alternativas, como tratamientos médicos para recuperar la salud de personas lesionadas, dictado o anulación de medidas administrativas por parte del Estado responsable, sanciones honoríficas, publicación de sentencias, reconocimiento de responsabilidades en actos públicos con presencia de las víctimas, etc. Todo ello siempre acompasado con la cesación del acto lesivo, la investigación en el Derecho Interno de las responsabilidades individuales y la prevención para el futuro.

56 Corte Interamericana de Derechos Humanos. Caso "Vargas Areco", párrafo 141. 
- Las normas de usuarios y consumidores son operativas y directamente aplicables.

- Las garantías para la protección de estos derechos deben proveer al requisito de eficacia, como las garantías de los demás derechos humanos.

- Los daños en derecho del consumo importan la vigencia de la reparación integral como aspecto de la tutela judicial efectiva. 


\section{REFERENCIAS}

- Alterini, Atilio Aníbal. "Las reformas a la ley de defensa del consumidor. Primera lectura, 20 años después”. La Ley, 1 (2008).

- Campos, Germán Bidart. Tratado Elemental de Derecho Constitucional. Tomo VI.

- Correa, José Luis. "Acciones de incidencia colectiva. Modificación de La Ley de Defensa del Consumidor”. La Ley (2008-F), 1106.

- Farina, Juan M. Defensa del consumidor y del usuario. Buenos Aires: Astrea, 2004.

- Faúndez Ledesma, Héctor. El sistema interamericano de protección de los derechos humanos. Aspectos institucionales y procesales. Tercera edición. Costa Rica: Instituto Interamericano de Derechos Humanos, 2004.

- Galdós, Jorge Mario. "La relación de consumo en la jurisprudencia de la Corte Suprema de Justicia de la Nación”. En Ley de Defensa del Consumidor. Comentada y anotada, Vázquez Ferreyra y Picasso Directores. Buenos Aires: La Ley, 2011, tomo III, pp. 33 y ss.

- Ghersi, Carlos A. "Responsabilidad del Estado. Daños por actos lícitos e ilícitos de sus funcionarios u órganos”. La Ley (2011-C), p. 149.

- Ghersi, C. y otros. Derecho y responsabilidades de las empresas y consumidores. Buenos Aires: Ediciones Organización Mora Libros, 1994.

- López Alfonsín, Marcelo. Derecho Ambiental. Buenos Aires: Astrea, 2012.

- Lorenzetti, Ricardo Luis. Consumidores. Santa Fe: Rubinzal-Culzoni, 2003, pp. 44-45.

- Manili, Pablo. "La difícil tarea de elaborar un concepto de los derechos humanos". Revista Jurídica de la UCES, 1 (1999).

- Marcelo Alejandro David. "Defensa de los consumidores y usuarios en el Derecho Nacional (Primera parte). Origen, y evolución social y legal del derecho de los consumidores y usuarios”. Suplemento de Derecho del Consumidor de El Dial, 3 de, 2006.

- Mosset Iturraspe y Lorenzetti. Defensa del Consumidor Ley 24.240. Buenos Aires: Rubinzal Culzoni.

- Nikken, Pedro. Manual de derechos humanos. Selección de materiales. Centro de Estudios de Derechos Humanos, Universidad Central de Venezuela, 2008.

- Pérez Bustamante, Laura. Derecho Social de Consumo. Buenos Aires: La Ley, 2004.

- Torres Traba, José M. "Utilidad procesal de las medidas cautelares atípicas. La tutela anticipada de los derechos y la medida innovativa”. En DJ 05/11/2008, 1913; DJ 2008-II, 1913.

- Villaragut, Marcelo; Calderón, Maximiliano Rafael. "El beneficio de gratuidad de La Ley de Defensa del Consumidor en la jurisprudencia de las Cámaras de Apelaciones de Córdoba”. LLC (noviembre de 2011), 1047.

Recibido 02/04/2014

Aprobado 17/04/2014 


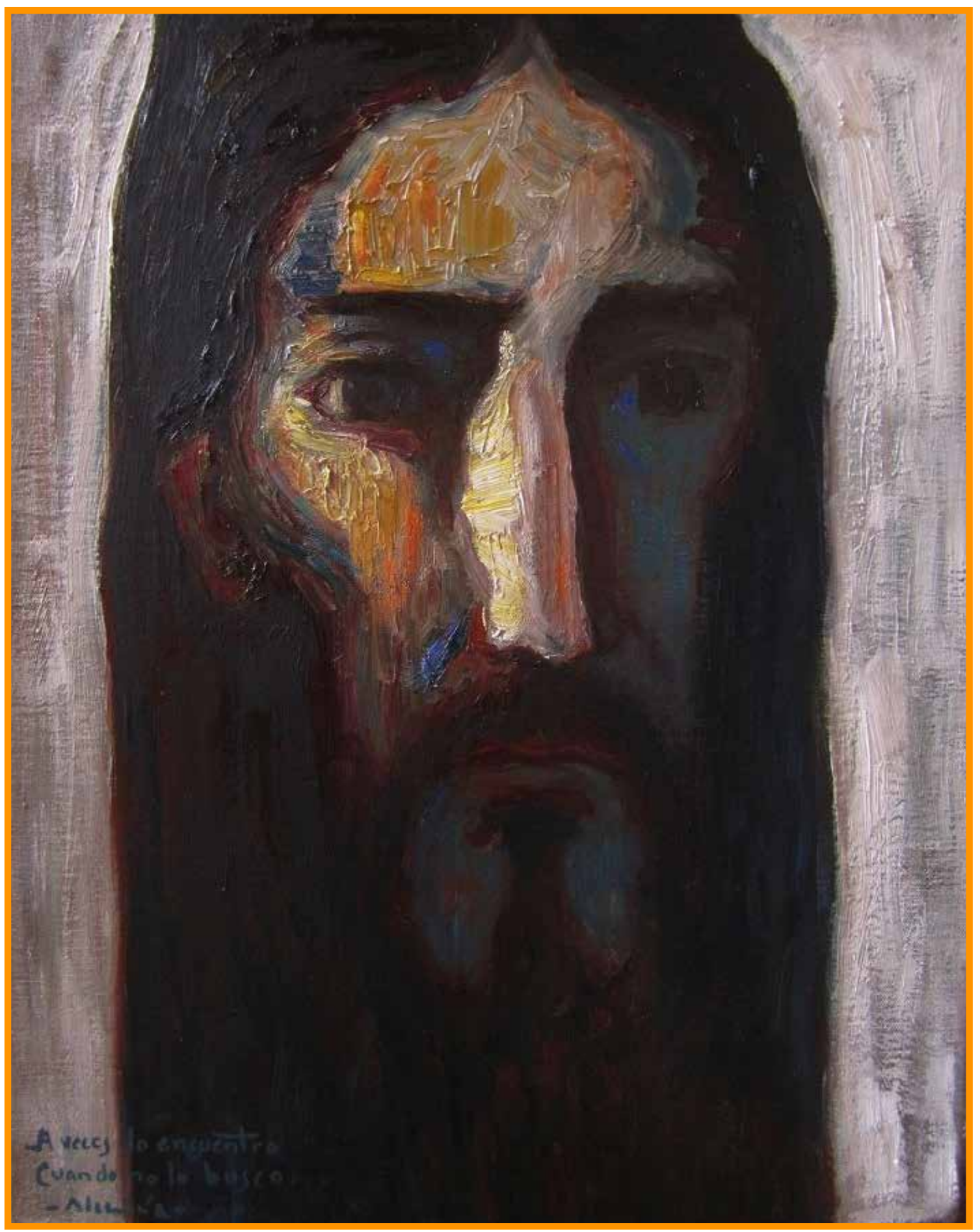

Cristo. Óleo sobre tela $(60 \times 50 \mathrm{~cm})$. 